\title{
Response of Two Brassica Species to the Toxic Effect of Different Copper Concentration
}

\author{
Khalid H. Alobaidi' ${ }^{1}$, Elena B. Bashmakova ${ }^{2}$, Valentina P. Kholodova ${ }^{2}$ \\ ${ }^{1}$ Department of Agricultural Biotechnology, College of Applied Biotechnology, Al-Nahrain University, \\ Baghdad, Iraq \\ ${ }^{2}$ Timiryazev Institute of Plant Physiology, Russian Academy of Science, Moscow, Russia \\ Email: khalid7877@yahoo.com
}

Received 4 May 2015; accepted 21 July 2015; published 27 July 2015

Copyright (C) 2015 by authors and Scientific Research Publishing Inc.

This work is licensed under the Creative Commons Attribution International License (CC BY). http://creativecommons.org/licenses/by/4.0/

(c) (i) Open Access

\begin{abstract}
One of the most important challenges in the ecosystem nowadays is the adaptation of plants to damaged environmental factors. Among them, an important attention is paid to the toxic effects of high concentrations of heavy metals (HM). Copper is essentially but highly toxic HM. In the work, first we established, plant's resistance comparison of the two studied Brassica species Brassica- $B$. $a l b a$, and $B$. napus - in higher concentrations of copper in the environment, and demonstrated that the two plants were potentially useful for phytoremediation of moderately polluted areas with copper. In plants of the genus Brassica grow in a hydroponic culture, experiments showed that the tested species referred to indicator plants. Results show the stability of the studied plants to the toxic effects of excessive copper levels, due to their proline accumulation ability. Studied plants, $B$. alba, and B. napus, can be used in selection practice as baselines to generate new plant varieties with increased resistance to heavy metals salts.
\end{abstract}

\section{Keywords}

Brassica alba, Brassica napus, Resistance to Copper, Phytoremediation

\section{Introduction}

Technogenic pollution by heavy metals (HM) is one of the most critical environmental problems [1] [2]. Heavy metals are chemical elements that have a density greater than $5 \mathrm{~g} / \mathrm{cm}^{3}$ and an atomic mass of $40 \mathrm{~d}$ [3] [4]. They pose a serious threat, primarily because of their high toxicity [5]. Plants growing on contaminated soil can absorb HM, and accumulate and transfer them to humans and animals in the use of plant products as food. Despite 
the fact that many HM, such as copper, zinc, cobalt, and iron, are essential elements, for normal growth and development of the organism at low concentration [6]. In high concentrations, they adversely affect both the plants and the human body. They accumulate in many organs causing various disorders, especially inhibition of growth and yield reduction, inhibition of photosynthesis and respiration, impaired protein synthesis and donor-acceptor relations, inactivation of key metabolic enzymes, the change of water and hormonal status and even the death of the organism [6] [7].

To clean the soil from HM pollution, scientists developed a variety of technologies, one of which is phytoremediation — a method that based on the use of plants to clean up contaminated sites [8] [9]. The most commonly used for this purpose phytoextraction method, which is based on the ability of certain species of plants, absorbs HM from the soil and accumulates them in the aerial organs [10]-[13].

Efficiency of the process Phytoextraction depends on the selection of plant species that not only accumulate HM in the aerial parts, but also produce large amounts of biomass [13]-[15].

Plants grow in contaminated sites, called "phytoremediators", above all, must be resistant to high concentrations of HM salts [16]-[18]. In addition, they need to grow quickly and produce large amounts of biomass, as well as contain substances that prevent eating them by herbivores to preserve the food chain from toxic heavy metals.

Selection of plant species tolerance to heavy metals is a key element in creating an effective phytoremediation technology. In the literature, there is evidence that the most resistant plants to higher concentrations of heavy metals in the soil are the representatives of the families of the cabbage, cereals and legumes [19].

Copper salts are one of the most toxic metals that contaminate soil. However, currently unknown species of plants have accumulated HM in large quantities, i.e. copper hyperaccumulator, although there is evidence as copper remediation in the study of plants Azollapiñata, Brassica juncea (mustard), Eichornia crassipes (water hyacinth), Helianthus annus L. (sunflower), Hydrocotyle umbellate L., Lemna minor L., Zygohyllum fabago L. [20].

\section{Materials and Methods}

The work was carried out on two species plants of genus Brassica: spring rapeseed B. napus (Westar Canadian selection), and wild-type B. alba seeds which were obtained from the Baghdad region of Iraq.

Seeds were cultivated in containers with perlite. Aged 10 - 14 days, -3 to 5 plants/ 1 liter dark plastic containers with a modified Hoagland-Snyder nutrient medium, without EDTA but with iron in the nitrate form (3 mg $\mathrm{Fe}\left(\mathrm{NO}_{3}\right)_{3} /$ liter). Plants were grown in phytotron chamber, where to maintain a constant temperature $23^{\circ} \mathrm{C}-25^{\circ} \mathrm{C}$ daytime and $18^{\circ} \mathrm{C}-20^{\circ} \mathrm{C}$ night, photoperiod $12 / 12$ (day/night) hours at $450 \mathrm{lux} / \mathrm{m}^{2}$ sek illumination intensity. The light source used metal halogen lamps (Philips, Korea) $400 \mathrm{~W}$ (2 Lamp each $1.5 \mathrm{~m}^{2}$ ). A complete replacement of the culture medium in the vessels every 5 days was done. In the experiments, 3 - 4 week plants were grown for 5 and10 days on a nutrient medium containing $\mathrm{CuSO}_{4}$ with a concentration of 10, 25, 50, 100 and $150 \mu \mathrm{Mol}$ (control $-0.25 \mu \mathrm{Mol})$. Measurement of fresh biomass of individual plant organs-leaves, roots-performed by standard methods. And we used analytical balances AB54-S (Mettler Toledo, Switzerland).

In the experiments for the determination of proline and content of metals, we used average sample of all the leaves, not counting the cotyledon. All experiments performed in triple biological replicates. The results were statistically processed and expressed as the arithmetic mean and the representativeness of the error standard deviation. The experimental results statistically processed using the program Excel.

\subsection{The Copper Content in the Plant Material}

Determination of the content of copper was performed by Golubkina method [21]. A weighed sample of previously dried plant material (typically $50 \mu \mathrm{g}$ ) placed in a test tube filled with a mixture of nitric acid $(1.6 \mathrm{~mL})$ and hydrochloric acid $(0.5 \mathrm{ml})$ and left overnight. The next day, the sample tubes placed in a preheated to a temperature of $110^{\circ} \mathrm{C}$ thermostat, incubated for $1 \mathrm{hr}$ then a further $2 \mathrm{~h}$ at $180^{\circ} \mathrm{C}$. To samples added one drop of concentrated hydrogen peroxide. The next day, decolourised. Transferred into measuring tube and adjusted with distilled water to a certain volume $(10-15 \mathrm{ml})$. Measuring the concentration of $\mathrm{Cu}$ carried out on atomic absorption spectrophotometer FM 400 (Labist, Russia).

\subsection{Content of Free Proline}

The free proline was determined using the acid ninhydrin reagent method [22]. A weighed sample of fresh plant 
leaves tissue $\left(50 \mathrm{mg}\right.$ ) transferred to microbiological test tubes; added $10 \mathrm{ml}$ of $100^{\circ} \mathrm{C}$ distilled water and placed in a boiling water bath. The result is a complete free proline extraction from the plant tissue. To assess the content of proline in $1 \mathrm{ml}$ the obtained extract added $1 \mathrm{ml}$ of glacial acetic acid and $1 \mathrm{ml}$ of ninhydrin reagent (30 $\mathrm{ml}$ of acetic acid $+20 \mathrm{ml}$ of $6 \mathrm{M}$ phosphoric acid $+1.25 \mathrm{~g}$ ninhydrin) incubated in a boiling water bath for 1 hour and then quickly cooled in ice. The color intensity was determined spectrophotometrically at $520 \mathrm{~nm}$ on a spectrophotometer “Thermo Fisher Scientific, Genesys 20” (USA).

\section{Results}

\subsection{Effect of Copper on the Growing of Plants}

By the end of the experiment, control plant variant $B$. napus accumulated relatively large biomass, whereas the growth of B. alba was slower.

However, the inhibitory effect of excessive concentrations of copper was very strong in the fresh plant biomass accumulation B. napus. Already starting with the lowest concentration of $10 \mu \mathrm{Mol} \mathrm{CuSO}_{4}$ reduction was after 5 days of exposure about $20 \%$ and after 10 days of exposure about $30 \%$ of control. At a concentration of $100-150 \mu \mathrm{Mol}$ copper in the medium, reduction of plants biomass in B. napus was $68 \%$ and $76 \%$ after 5 days, $71 \%$ and $77 \%$ after 10 days of exposure than plants growing in standard copper content $(0.25 \mu \mathrm{Mol})$. In contrast, the growth of plants B. alba at high concentrations of copper in the media affected weakly than B. napus, maximal reduction was $64 \%$ of controls. There was even more obvious difference between the growths of two species. Inhibitory effect is strongly manifested in the accumulation of fresh plant biomass $B$. napus, but throughout the range of $\mathrm{CuSO}_{4}$ concentrations used-from 10 to $150 \mu \mathrm{Mo}-B$. alba were less affected when compared to $B$. napus (Table 1). So there are some differences in stability between species for the benefit of B. alba.

\subsection{Copper Accumulation in Plant Tissues}

One of the most important parameters that determine the phytoremediation potential of culture is accumulated heavy metals in aerial plant organs [23]. Therefore, in our experiment, it was necessary to assess the ability of the studied plants in the accumulation of copper in plants organs (leaves and roots). founded that when growth in medium contain standard concentration of $\mathrm{CuSO}_{4}(0.25 \mu \mathrm{Mol})$, copper concentrations in the organs of the two young plants species studied almost identical, being in the range of $21-30 \mu \mathrm{g} / \mathrm{g}$ dry weight $5-10$ days exposure in the roots of $B$. alba and $20-24 \mu \mathrm{g} / \mathrm{g}$ dry weight $5-10$ days exposure in the roots of B. napus (Table 2) and 7 - $10 \mu \mathrm{g} / \mathrm{g}$ dry weight 5 - 10 days exposure in the leaves of $B$. alba and $7-11 \mu \mathrm{g} / \mathrm{g}$ dry weight 5 - 10 days exposure in the leaves of B. napus (Table 3).

However, introducing a large excess of $\mathrm{CuSO}_{4}$ in the nutrient solution resulted in the accumulation of copper in studied plant at high concentrations. Brassica plant species studied did not differ in the content of copper in the roots of control options (Table 2). Increasing the concentration of $\mathrm{CuSO}_{4}$ in the medium resulted in a strong accumulation of copper in the roots of plants of all two species studied of Brassica. It was seen that for all used variants of excess copper in the environment its accumulation in the roots of $B$. alba exceed the data obtained for plant B. napus. At the maximum concentration of $\mathrm{CuSO}_{4}$ in the medium $(150 \mu \mathrm{Mol})$ excess over control values for plants $B$. napus was 61 -folds, after 5 days and 98 -folds after 10 days, whereas B. alba 92-folds after 5 days and 114-folds after 10 days.The copper content in leaves of control options studied Brassica species was quite close (Table 3).

\section{Table 1. $\mathrm{CuSO}_{4}$ effect on growth of young plants. Fresh biomass (g).}

\begin{tabular}{ccccc}
\hline \multirow{2}{*}{ Variants } & \multicolumn{2}{c}{ Exposure - 5 days } & \multicolumn{2}{c}{ Exposure - 10 days } \\
\cline { 2 - 5 } & B. alba & B. napus & B. alba & B. napus \\
\hline $0.25 \mu \mathrm{Mol}$. & $1.45 \pm 0.18$ & $1.86 \pm 0.20$ & $2.72 \pm 0.20$ & $3.71 \pm 0.25$ \\
$10 \mu \mathrm{Mol}$. & $1.22 \pm 0.18$ & $1.52 \pm 0.18$ & $1.91 \pm 0.16$ & $2.51 \pm 0.24$ \\
$25 \mu \mathrm{Mol}$. & $0.93 \pm 0.16$ & $1.17 \pm 0.15$ & $1.79 \pm 0.17$ & $2.09 \pm 0.20$ \\
$50 \mu \mathrm{Mol}$. & $0.85 \pm 0.15$ & $0.82 \pm 0.16$ & $1.43 \pm 0.16$ & $1.35 \pm 0.19$ \\
$100 \mu \mathrm{Mol}$. & $0.72 \pm 0.12$ & $0.60 \pm 0.13$ & $1.12 \pm 0.13$ & $1.07 \pm 0.13$ \\
$150 \mu \mathrm{Mol}$. & $0.61 \pm 0.08$ & $0.44 \pm 0.10$ & $0.99 \pm 0.11$ & $0.85 \pm 0.12$ \\
\hline
\end{tabular}


Table 2. Cu content in the roots. $\mu \mathrm{g} / \mathrm{g}$ dry wt.

\begin{tabular}{ccccc}
\hline \multirow{2}{*}{ Variants } & \multicolumn{2}{c}{ Exposure -5 days } & \multicolumn{2}{c}{ Exposure - 10 days } \\
\cline { 2 - 5 } & B. alba & B. napus & B. alba & B. napus \\
\hline $0.25 \mu$ Mol. & $21 \pm 0.9$ & $20 \pm 0.9$ & $30 \pm 0.9$ & $24 \pm 0.9$ \\
$10 \mu$ Mol. & $200 \pm 1.8$ & $197 \pm 2.5$ & $240 \pm 1.5$ & $297 \pm 2.0$ \\
$25 \mu$ Mol. & $340 \pm 5.0$ & $280 \pm 5.0$ & $540 \pm 4.0$ & $580 \pm 5.0$ \\
$50 \mu$ Mol. & $709 \pm 9.0$ & $578 \pm 7.0$ & $1196 \pm 9.0$ & $781 \pm 8.0$ \\
$100 \mu$ Mol. & $1484 \pm 10$ & $991 \pm 10$ & $2313 \pm 10$ & $1527 \pm 11$ \\
$150 \mu$ Mol. & $1942 \pm 11$ & $1231 \pm 10$ & $3422 \pm 11$ & $2362 \pm 12$ \\
\hline
\end{tabular}

Table 3. Cu content in the leaves. $\mu \mathrm{g} / \mathrm{g}$ dry wt.

\begin{tabular}{ccccc}
\hline \multirow{2}{*}{ Variants } & \multicolumn{2}{c}{ Exposure -5 days } & \multicolumn{2}{c}{ Exposure - 10 days } \\
\cline { 2 - 4 } & B. alba & B. napus & B. alba & B. napus \\
\hline $0.25 \mu \mathrm{Mol}$. & $7 \pm 0.4$ & $7 \pm 0.5$ & $10 \pm 0.3$ & $11 \pm 0.6$ \\
$10 \mu \mathrm{Mol}$. & $12 \pm 0.3$ & $13 \pm 0.8$ & $17 \pm 0.4$ & $20 \pm 0.6$ \\
$25 \mu \mathrm{Mol}$. & $19 \pm 0.4$ & $22 \pm 0.6$ & $24 \pm 0.5$ & $37 \pm 1.0$ \\
$50 \mu \mathrm{Mol}$. & $26 \pm 0.5$ & $30 \pm 1.0$ & $51 \pm 0.7$ & $59 \pm 1.5$ \\
$100 \mu \mathrm{Mol}$. & $40 \pm 0.8$ & $44 \pm 2.0$ & $63 \pm 0.9$ & $80 \pm 2.0$ \\
$150 \mu \mathrm{Mol}$. & $46 \pm 1.0$ & $49 \pm 1.5$ & $76 \pm 1.0$ & \\
\hline
\end{tabular}

In addition, there were no significant differences in the concentration of the copper accumulated in the leaves of $B$. napus with increasing concentration of $\mathrm{CuSO}_{4}$ in the medium up to $150 \mu \mathrm{Mol}$ after 5 days of exposure, but after 10 days of exposure differences in accumulation significantly observed especially in concentration 50 $\mu \mathrm{Mol}$ in B. alba. This difference manifested both in absolute terms and in relation to the concentration in the leaves of control plants of the same species. Particularly evident dominance B. alba in the calculation with respect to the values for the control group of the same species. Thus, the maximum concentration of copper accumulated in the leaves than the corresponding values of the control plants variant B. alba 5.1, 6.3 and 7.6 times at 50,100 and $150 \mu \mathrm{Mol}$ respectively after 10 days exposure, while in B. napus 3, 5 and 7 times at 50, 100 and 150 $\mu \mathrm{Mol}$ respectively after 10 days exposure. Thus, the increased resistance of plants $B$. alba and B. napus to excess $\mathrm{CuSO}_{4}$ content in the medium was not associated with the restriction of the absorption of copper ions by roots and translocation in their escape from the plants of these species (Table 2 and Table 3). On the contrary, it was realized under conditions of slightly higher copper accumulation in the roots and leaves of the plant $B$. alba in comparison with plant $B$. napus.

\subsection{Effect of Copper on the Content of Free Proline}

In the study of the possible reasons for the differences in the resistance to excessive concentrations of copper in the medium between the plants, Brassica species conducted to study the influence of stress factors on the proline content in relation to its known function as a chemical chaperone. It shown that, the level of proline in the leaves of plants species studied equal. Proline concentration in the control variant plants B. alba and B. napus was close $0.8-1.0 \mu \mathrm{Mol} / \mathrm{g}$ wet mass of leaves (Table 4). Increased concentrations of $\mathrm{CuSO}_{4}$ in the medium caused a strong accumulation of proline in leaves of the studied Brassica species. Even at entering $10 \mu \mathrm{Mol} \mathrm{CuSO}_{4}$ in the medium concentration of proline in leaves was increased to 4.3 - 6 times after 5 days and 5 - 7 after 10 days in relation to the values of the control options for the respective species. Increasing copper concentrations, results significantly in increasing prolin concentration in leaves of B. alba significantly which exceeded that of B. napus. The maximum accumulation of proline to $27.9 \mu \mathrm{Mol} / \mathrm{g}$ wet mass of leaves was found in the leaves of plants $B$. 
Table 4. Proline content in leaves of 2 Brassica species ( $\mu \mathrm{Mol} / \mathrm{g}$ wet mass 5 and 10 days).

\begin{tabular}{|c|c|c|c|c|}
\hline \multirow{2}{*}{ Variants } & \multicolumn{2}{|c|}{ Exposure - 5 days } & \multicolumn{2}{|c|}{ Exposure - 10 days } \\
\hline & B. alba & B. napus & B. alba & B. napus \\
\hline $0.25 \mu \mathrm{Mol}$ & 0.8 & 0.8 & 0.8 & 1.0 \\
\hline $10 \mu \mathrm{Mol}$ & 4.8 & 3.5 & 5.9 & 4.8 \\
\hline $25 \mu \mathrm{Mol}$ & 5.4 & 5.1 & 7.7 & 6.2 \\
\hline $50 \mu \mathrm{Mol}$ & 7.3 & 6.7 & 10.3 & 8.8 \\
\hline $100 \mu \mathrm{Mol}$. & 11.5 & 8.5 & 14.4 & 14.7 \\
\hline $150 \mu \mathrm{Mol}$. & 21.4 & 11.5 & 27.9 & 18.7 \\
\hline
\end{tabular}

alba, at $150 \mu \mathrm{M} \mathrm{CuSO}_{4}$ after 10 days of exposure (Table 4). As a result, the maximum proline content exceeded the value of control options of the respective species of plants B. alba about 33 times of the control, whereas $B$. napus about 19 times from control.

These results indicate a significant role of proline in plants adaptation of $B$. alba and B. napus to toxic effect of high concentrations $\mathrm{CuSO}_{4}$ in a nutrient medium

\section{Discussion}

Copper is one of the most HM as essential elements in trace amount, which is necessary for the life of all living organisms. Studies have shown that plants grown in Cu-contaminated soil usually accumulate high concentration of copper in their tissues. As a result, a number of physiological and toxicological responses take place in plants depending on the concentration of copper [24] [25].

Small number of known plant species, at which the level of copper accumulation in aerial organs exceed 1000 mg per $1 \mathrm{~g}$ dry weight [26], which is a determinant to classify them as hyperaccumulators of copper. Although none of the species examined in the present study can be attributed to this small group, however, in terms of phytoremediation, this is not a definitive barrier to the use of plants of the genus Brassica.

Many studies show that different species of the genus Brassica have the ability to accumulate $\mathrm{Cu}$ in tissues with substantial concentrations [27]. Different species of Brassica showed variation for biomass accumulation and concentration of copper. B. alba were less than Brassica napus in the production of large biomass of shoot as well as having a high concentration of copper in shoots and roots. Previously reported that $B$. juncea shows good accumulation of several heavy metals, including copper [27] [28]. Fargasova reported that B. alba have the ability to accumulate many heavy metals, including copper in the root and in greater numbers than in the shoot of plants [29]. Rossi also demonstrated that the roots of Brassica napus accumulated several-fold more copper than the aerial organs, which is in accord with the present results [30].

In this study, it was found that, although the accumulation of aboveground biomass in plants B. alba lagged behind Brassica napus, copper accumulation in the leaves of plants of this species considerably exceeded plant Brassica napus. Moreover, B. alba showed greater resistance to the excess copper at the stage young plants grow in comparison with Brassica napus. The ability to grow plants with a significant amount of biomass and accumulation of copper in large amounts in the roots and shoots of $B$. alba showed fairly good resistance to high concentrations of $\mathrm{CuSO}_{4}$, making it promising for further research in respect to phytoremediation [29].

\section{Conclusion}

The results of this study allow us to consider B. alba as a promising species for phytoremediation of moderately contaminated areas as $B$. alba accumulates copper in the aerial organs ( $76 \mu \mathrm{g} / \mathrm{g}$ dry wt.) at a relatively higher biomass accumulation (about $1 \mathrm{~g} /$ plant) comparing with Brassica napus $80 \mu \mathrm{g} / \mathrm{g}$ dry wt. for the accumulation of copper with $0.85 \mathrm{~g}$ biomass. From all the above results, we confidently recommend $B$. alba for phytoremediate in contaminated copper territory. However, a more detailed study should be performed for the ability of this type of plant to grow well in the experimental soil culture. Also further genetic study is important to determine the 
genes that involve in stress tolerance.

\section{References}

[1] Waoo, A.A., Khare, S. and Ganguli, S. (2014) Extraction and Analysis of Heavy Metals from Soil and Plants in the Industrial Area Govindpura, Bhopal. Journal of Environment and Human, 1, 158-164.

[2] Body, P.E., Inglis, G., Dolan, P.R. and Mulcahy, D.E. (1991) Environmental Lead: A Review. Critical Reviews in Environmental Science and Technology, 20, 299-310. http://dx.doi.org/10.1080/10643389109388403

[3] Kuznetsov, V.V. and Dmitrieva, G.A. (2011) Plant Physiology. Higher School Publishing, Moscow, $744-748$ (in Russian).

[4] Koshkin, E.I. (2010) Physiology of Horticultural Crops Sustainability. Drofa, Moscow, 638 (in Russian).

[5] Papagiannis, I., Kagalou, I., Leonardos, J., Petridis, D. and Kalfakaou, V. (2004) Copper and Zinc in Four Freshwater Fish Species from Lake Pamvotis (Greece). Environment International, 30, 357-362. http://dx.doi.org/10.1016/j.envint.2003.08.002

[6] Kholodova, V.P., Ivanova, E.M. and Kuznetsov, V.V. (2011) Initial Step of Copper Detoxification: Outside and Inside of the Plant Cell. In: Sherameti, I. and Varma, A., Eds., Detoxification of Heavy Metals, Springer Berlin, 143-167. http://dx.doi.org/10.1007/978-3-642-21408-0 8

[7] Titov, A.F., Talanova, V.V., Kaznina, N.M. and Laidinen, G.F. (2007) Resistance of Plants to Heavy Metals. Karelian Research Centre of Russian Academy of Sciences, Petrozavodsk, 172 p (in Russian).

[8] Buravtsev, V.N. and Krylova, N.P. (2005) Modern Technological Schemes of Phytoremediation of Polluted Soils. Agricultural Biology, 5, 67-73 (in Russian).

[9] Krämer, U. (2005) Phytoremediation: Novel Approaches to Cleaning up Polluted Soils. Current Opinion in Biotechnology, 16, 133-141. http://dx.doi.org/10.1016/j.copbio.2005.02.006

[10] Barbafieri, M., Dadea, C., Tassi, E., Bretzel, F. and Fanfani, L. (2011) Uptake of Heavy Metals by Native Species Growing in a Mining Area in Sardinia. International Journal of Phytoremediation, 13, 985-997.

[11] Koshkin, E. and Vagun, I. (2010) Phytoremediation Capability of Brassica napus Grown on Soils, Contaminated with Heavy Metals. FESPB-XVII Congress of the Federation of European Societies of Plant Biology, Book of Abstracts, Valencia, 4-9 July 2010, 54.

[12] Chaney, R.L., Malik, M., Li, Y.M., Brown, S.L., Brewer, E.P., Angle, J.S. and Baker, A.J.M. (1997) Phytoremediation of Soil Metals. Current Opinion in Biotechnology, 8, 279-284. http://dx.doi.org/10.1016/S0958-1669(97)80004-3

[13] Raskin, I., Kumar, P.B., Dushenkov, V. and Salt, D.E. (1994) Bioconcentration of Heavy Metals by Plants. Current Opinion in Biotechnology, 5, 285-290. http://dx.doi.org/10.1016/0958-1669(94)90030-2

[14] Jadia, C.D. and Fulekar, M.H. (2009) Phytoremediation of Heavy Metals: Recent Techniques. African Journal of Biotechnology, 8, 921-928.

[15] Das, M. and Maiti, S.K. (2007) Metal Accumulation in Five Native Plants Growing on Abandoned Cu-Tailing Ponds. Applied Ecology and Environmental Research, 5, 27-35. http://dx.doi.org/10.15666/aeer/0501_027035

[16] Schmidt, U. (2003) Enhancing Phytoextraction: The Effect of Chemical Soil Manipulation on Mobility, Plant Accumulation, and Leaching of Heavy Metals. Journal of Environmental Quality, 32, 1939-1954. http://dx.doi.org/10.2134/jeq2003.1939

[17] Bricker, T.J., Pichtel, J., Brown, H.J. and Simmons, M. (2001) Phytoextraction of Pb and Cd from a Superfund Soil: Effects of Amendments and Croppings. Journal of Environmental Science and Health, 36, 1597-1610. http://dx.doi.org/10.1081/ESE-100106245

[18] Salt, D.E., Blaylockm, M., Kumar, P.B.A.N., Dushenkov, V., Ensley, B.D., Chet, I. and Raskin, I. (1995) Phytoremediation: A Novel Strategy for the Removal of Toxic Metals from the Environment Using Plants. Nature Biotechnology, 13, 468-474. http://dx.doi.org/10.1038/nbt0595-468

[19] Prasad, M.N.V. and Freitas, H. (1999) Biotechnological and Bioremediation Strategies for Serpentine Soils and Spoils. Electronic Journal of Biotechnology, 2, 35-50.

[20] Prasad, M.N.V. and Strzalka, K. (1999) Impact of Heavy Metals on Photosynthesis. In: Prasad, M.N.V. and Hagemeyer, J., Eds., Heavy Metal Stress in Plants, Springer, Berlin, 117-138. http://dx.doi.org/10.1007/978-3-662-07745-0_6

[21] Mabry, T.J., Markham, K.R. and Thoma, M.B. (1970) The Systematic Identification of Flavonoids. Springer, New York, 261-266. http://dx.doi.org/10.1007/978-3-642-88458-0

[22] Bates, L.S., Waldren, R.P. and Teare, I.D. (1973) Rapid Determination of Free Proline for Water-Stress Studies. Plant and Soil, 39, 205-207. 
[23] Padmavathiamma, P.K. and Li, L.Y. (2007) Phytoremediation Technology: Hyper-Accumulation Metals in Plants. Water, Air, and Soil Pollution, 184, 105-126. http://dx.doi.org/10.1007/s11270-007-9401-5

[24] Mateos-Naranjo, E., Andrades-Moreno, L., Cambrollé, J. and Perez-Martin, A. (2013) Assessing the Effect of Copper on Growth, Copper Accumulation and Physiological Responses of Grazing Species Atriplex halimus: Ecotoxicological Implications. Ecotoxicology and Environmental Safety, 90, 136-142. http://dx.doi.org/10.1016/j.ecoenv.2012.12.020

[25] Xiong, Z.T. and Wang, H. (2005) Copper Toxicity and Bioaccumulation in Chinese Cabbage (Brassica pekinensis Rupr.). Environmental Toxicology, 20, 188-194. http://dx.doi.org/10.1002/tox.20094

[26] Fernandes, J.C. and Henriques, F.S. (1991) Biochemical, Physiological, and Structural Effects of Excess Copper in Plants. The Botanical Review, 57, 246-273. http://dx.doi.org/10.1007/BF02858564

[27] Kramer, U. (2010) Metal Hyperaccumulation in Plants. Annual Review of Plant Biology, 61, 517-534. http://dx.doi.org/10.1146/annurev-arplant-042809-112156

[28] Purakayastha, T.J., Viswanath, T., Bhadraray, S., Chhonkar, P.K., Adhikari, P.P. and Suribabu, K. (2008) Phytoextraction of Zinc, Copper, Nickel and Lead from a Contaminated Soil by Different Species of Brassica. International Journal of Phytoremediation, 10, 61-72.

[29] Fargasova, A. (2001) Phytotoxic Effect of Cd, Zn, Pb, Cu and Fe on Sinapis alba L. Seedlings and Their Accumulation in Roots and Shoots. Biologia Plantarum, 3, 471-473. http://dx.doi.org/10.1023/A:1012456507827

[30] Rossi, G., Figliolia, A. and Socciarelli, S. (2004) Zinc and Cooper Bioaccumulation in Brassica napus at Flowering and Maturation. Engineering in Life Sciences, 4, 271-275. http://dx.doi.org/10.1002/elsc.200420028 